\title{
Estimating a Payment Vehicle for Financing Nourishment of Residential Beaches using a Spatial-lag Hedonic Property Price Model
}

\author{
Running Head: Hedonic Value Capture Tax \\ O. Ashton Morgan \\ Assistant Professor \\ Department of Economics \\ 3094 Raley Hall \\ Appalachian State University \\ Boone, NC 28608 \\ morganoa@appstate.edu \\ Stuart E. Hamilton \\ GIS Program Director \\ 225 Morton Hall \\ The College of William and Mary \\ Williamsburg, VA 23187 \\ sehamilton@wm.edu
}

\begin{abstract}
Beach nourishment projects are common methods for coastal states to protect beaches and property from the natural erosive process. However, while the beneficiaries of beach nourishment tend to be local property owners and recreators, projects are typically funded at the state level. Based on the benefit principle, as local residents receive more of the erosion protection benefits of the nourishment projects, we estimate a value capture tax, designed to levy the financing burden in a manner that approximates the distribution of benefits. The benefits of nourishment projects to coastal property owners are estimated using the results from a spatial-lag hedonic model that controls for viewshed effects.
\end{abstract}




\section{Introduction}

Beach erosion can be a major threat to a natural resource that provides significant benefits to local homeowners as well as local and non-local recreators. At the national level, the federal government is expected to spend more than $\$ 6$ billion over the next fifty years to widen beaches (Parsons and Noailly 2004). In Florida, a state that thrives economically from maintaining its coastline, approximately $59 \%$ of the 825 miles of state beaches are experiencing erosion, of which 387 miles (47\%) are experiencing critical erosion that threatens recreational, cultural, and environmental interests, as well as future coastal development (FDEP 2008). Under the Beach and Shoreline Preservation Act of 1965, the Florida Beach Erosion Control Program implements beach management planning recommendations and works in conjunction with local, state, and federal government entities. Currently, these entities manage over 192 miles of restored beaches in Florida, and through the fiscal year 2006, over $\$ 582$ million had been appropriated by the Legislature for beach erosion control activities as well as hurricane recovery (FDEP 2008)

There are essentially three strategies for managing beach erosion. The first method is shoreline armoring. This involves the onshore construction of hard structures such as riprap, bulkhead, groins and seawalls, designed to reflect and absorb wave energy. Also, offshore structures, such as breakwaters and sills can be constructed to dissipate the energy of incoming waves. While many coastal communities around the U.S. use shoreline armoring, opponents of the strategy cite several negative impacts, including the 
adverse effects on adjacent shorelines, a decline in recreation due to the reduced aesthetic quality of the beach, and environmental effects, such as loss of wildlife habitat.

The second strategy is beach nourishment. Typically, sand is pumped onshore from an offshore location. Bulldozers then build up the new sand on the beach until it meets a predesignated specification. While largely avoiding the negative aesthetic impacts of shoreline armoring, nourishment can be an expensive strategy and only represents a temporary fix, often requiring further rounds of additional nourishment at a future date (Pilkey and Dixon 1996; Pompe and Rinehart 1995). Also, there are general concerns regarding the impact of dredging on sea floor habitats and marine life as a result of poorly designed or executed nourishment projects.

The third strategy is natural retreat. Under this option, as shoreline erosion is an inevitable consequence for many coastal areas, coastlines are allowed to erode naturally without any structural or engineering intervention. Retreat involves a policy of removing houses, stores and other infrastructure that would otherwise be lost to the short and medium term erosive process. Over the long term, new structures are built at a distance sufficiently inland as to not form a risk to the erosive process. Some recent research has considered the relative efficiency of the different strategies. For example, Parson and Powell (2001) state that while a natural retreat policy is clearly the least cost option in terms of the monetary cost, society incurs a loss of productive land, capital loss in the form of lost housing and commercial structures, and proximity loss for structures that would otherwise be located close to the coastline. As the monetary costs of shoreline armoring and nourishment can be high and also recurring, Parsons and Powell 2001 
consider the costs of beach retreat along the Delaware coastline. They estimate that the cost of beach retreat to be $\$ 291$ (\$2000) million over a 50 year period, while the present value cost of the existing nourishment program is substantially less at $\$ 60$ million (\$2000). Landry et al. (2003) consider the relative efficiency of the three strategies in terms of the recreational benefits, property value effects, and management costs. They find that while shoreline armoring is the least desirable option, the relative desirability for retreat versus nourishment depends upon how management costs change over time and the realized erosion rate.

Controversy surrounds all potential erosion protection measures as all impose costs on society. Adding further weight to concerns involves the method of project financing as most projects use a combination of state and federal dollars. In Florida, a large portion, if not all of the state's funding expenses, are financed through a tourist development tax (also known as a bed tax), levied on rental properties or hotel/motel accommodations. As such, while the beneficiaries of the projects tend to be local residents and beach users, the method of financing imposes a disproportionately large burden on non-local visitors, via the bed tax, and the general population, via federal taxes. Even among the local beneficiaries of erosion control projects, inequalities can exist as local residents with properties closer to the coast accrue a larger proportion of recreation and storm protection benefits associated with beach nourishment projects than property owners further inland (Parsons and Noailly 2004). ${ }^{1}$

\footnotetext{
${ }^{1}$ Not all households adjacent to the shoreline perceive beach nourishment to provide benefits. Two groups (Save Our Beaches and Stop the Beach Renourishment, Inc.) in Walton County, FL, took a legal battle to the Florida Supreme Court, arguing that renourishment infringed on their property rights as the state was placing renourishment sand on their property without their consent. In September, 2008, after a four-year
} 
The purpose of this paper is to provide a model that estimates an equitable and feasible taxation policy for beach nourishment projects based on the benefit principle of taxation. In developing a taxation policy, the underlying proposition is that the distribution of financing the projects should reflect the distribution of benefits as much possible. Black et al. (1990) outlined the three steps necessary to adhere to such a taxation system as identifying beneficiaries, measuring the benefits from the renourishment projects, and designing the tax to levy the financing burden in a manner that approximates the distribution of benefits. They reasoned that the preferred method of financing projects is a combination of local property taxes and beach access fees. As such, property taxes capture the benefits attributable to local property owners while beach access fees capture the benefits to non-resident beach visitors. We follow the model by Parsons and Noailly (2004) by focusing on a tax on local residents, also known as a value capture tax, as it captures the benefits of nourishment projects to local residents in the capitalized value of coastal properties. ${ }^{2}$ As such, the beneficiaries of nourishment projects are identified as local residents. The benefits to coastal property owners are estimated using the proximity values in a hedonic property price model, then, the value capture tax is designed assuming that the benefits of nourishment projects are capitalized into property prices in the same proportion as the properties' proximity values. Overall, the value capture tax provides a more equitable method of project financing as, by definition, those residents

battle, the Florida Supreme Court ruled that the State's Beach and Shoreline Preservation Act is constitutional.

${ }^{2}$ As the site of interest is a residential beach and the focus of the paper is to provide an equitable property tax, we do not include a beach access fee as part of the tax policy. 
living closer to the beach receive greater benefits from nourishment projects, and so, under this taxation system, pay a greater share of the financing burden.

We augment previous work that considers beach protection fees in a couple of ways (Black et al. 1990; Pompe and Rinehart 1999; Parsons and Noailly 2004). First, we control for spatial autocorrelation among property sales prices. Spatial issues are receiving increased attention in recent hedonic research (Patterson and Boyle 2002; Bin et al. 2008). While most hedonic studies include distance-based measures to an amenity or resource to measure proximity value, they typically do not control for spatial dependence between home sales prices. However, research suggests that property values for homes in common neighborhoods can be interdependent as they may share similar housing characteristics and location amenities (Paterson and Boyle 2002; Kim et al.2003; Bin et al. 2008). That is, the price of a home can be highly correlated with the price and quality of neighboring properties. As such, interdependence can exist among property sales prices due to the proximity of homes to one another. Spatial autocorrelation measures the level, nature, and strength of interdependence. The nature of spatial autocorrelation may be positive or negative. A positive relationship indicates that properties in close proximity are more likely to have similar values, while a negative relationship implies that one is less likely to observe similar property values for homes proximate to one another. Failure to correct for spatial dependence can violate the assumption of uncorrelated error terms and lead to biased and inconsistent estimates on the proximity variables, and inefficient parameter estimates for the other variables in the hedonic model (Irwin and Bockstael 2001). To correct for likely spatial autocorrelation, 
we create a spatial weights matrix that reflects the structure of the hypothesized spatial dependence. We use a contiguity matrix consisting of binary elements equal to 1 if two properties are within 100 meters of each other, zero otherwise. ${ }^{3}$

The research is also innovative as we incorporate recent advances in Geographic Information System (GIS) techniques to measure the viewshed from each property. The critical element in deriving a value capture tax is to measure the implicit value associated with locating a property close to the shoreline. Typically, proximity value in hedonic analyses is measured by estimating the Euclidean distance between each property in the dataset and the shoreline. However, we argue that proximity value is comprised of two separate factors; namely beach access and view of the coastline. Simply using a distance-based measure assumes that homes closer to the shoreline with better access also have an improved view. In a coastal community, this is not always the case, as dunes and other vegetation can obstruct the view of homes closer to the shoreline. As such, homes located farther back from the shoreline may have an improved view. ${ }^{4} \mathrm{We}$ argue that the benefits to local homeowners from nourishment projects are best captured by their access values, and so, disentangling the two effects permits isolating access value for use in estimating the value capture tax.

\footnotetext{
${ }^{3}$ As there is little formal evidence regarding the choice of weighting matrix (Anselin 2002), we chose a contiguity matrix that identifies non-zero elements for properties within a 100 meter distance based on our knowledge and observations of the study area and comparing the fits of a range of model specifications with different weighting distances.

${ }^{4}$ For example, properties five rows back from the shoreline have an average viewshed angle of 23.6 degrees compared to 12.6 degrees for properties four rows back.
} 
While access is relatively easy to capture using basic GIS techniques, adequately capturing view has proven to be more problematical in other hedonic research. Earlier work used single or scale dummies as proxies for a property's view (Pompe and Rinehart 1995; Doss and Taff 1996; Bond et al. 2002; Tse 2002; Bourassa et al. 2003). For example, Bensen et al. (1997) used three dummy variables (ocean front, unobstructed ocean view, and partial ocean view) to capture property views in Washington State, while Bourassa et al. (2003) used narrow, medium, and wide definitions of view to indicate the quality of a lake view on property values in Auckland, New Zealand. More recently, due to advances in GIS techniques, some researchers have measured a property's viewshed to provide a more precise and objective measure of view (Patterson and Boyle 2002; Bin et al. 2008). Lidar data provides information on the topographic surface of the coastal area, including property structures, dunes, and other vegetation. A view from each property can then be constructed that accurately accounts for other structures and vegetation that may obstruct a property's view of the shoreline. View is captured by measuring the degree of viewshed from each property. A critical component in measuring view is to determine the observation point from each property. For each parcel, we simulated the highest livable story window observation point. For flat roofed homes, we used an observation point of 1.5 meters below the roof level. For traditional roofed homes, we used a measure of 3 meters below the roof level. The maximum view of the shoreline can be 180 degrees. Overall, use of lidar data provides an objective and continuous measure of each property's viewshed that circumvents many of the problems inherent in previous view classifications. 


\section{Site of Interest - Pensacola Beach, Florida}

The area of interest for this study is Pensacola Beach, located in Escambia County, the western most county in Florida. The warm Gulf of Mexico waters and white sands serve to attract visitors year-round, principally from the Panhandle area, Alabama, Mississippi, and Louisiana. Tourism drives local economic development with a number of the main hotel chains, local restaurant and bars located on the beach. There are 281 single family residences along a 2-mile strip of residential units on Pensacola Beach that provide the focus for the analysis. The residential strip is approximately 200 meters wide with the average property in the sample located 112 meters from the shoreline.

Its location on the Gulf of Mexico makes the beach vulnerable from wave energy and storm activity. Hurricane Ivan, which made landfall in 2004 caused damage to properties across the county, while Katrina one year later caused flooding issues along coastal areas. There have been two renourishment projects over the last seven-year period. The first restoration in $2002-2003$ cost $\$ 15.7 \mathrm{~m}$ and was paid for principally by the state with some local contribution. In 2005-2006 there was an "extraordinary" post-Katrina restoration costing $\$ 14.2 \mathrm{~m}$, funded by FEMA plus some local funding. The renourishment projects provide storm protection benefits to residential and commercial properties. The projects also maintain the beach width, providing recreation benefits to local and visiting beach users. $^{5}$

\footnotetext{
${ }^{5}$ Random utility models and willingness to pay estimates provide evidence of recreational benefits for users of wider beaches [Parsons et al. (1999); Landry et al. (2003).]
} 
Property prices and home attribute data for homes sold between 1998 and 2007 are derived from the Pensacola Realtors Association database. ${ }^{6}$ Property sales prices are adjusted to 2007 prices using the consumer price index for housing. Descriptive statistics are presented in Table 1. Of the 281 single family residences on the beach, we obtained sales data for 101 properties. From this sample, the average viewshed is measured as 42 degrees of shoreline. The average property sales price over the period is $\$ 577,781$, while the average home is 30 years of age, 1,853 square feet, with two bathrooms, and a onecar garage.

\section{Hedonic Property Price Model}

Hedonic property price models are based on the theory of consumer behavior. The theory suggests that households value a good because they value the characteristics of the good rather than the good itself. In hedonic property price valuations, the price of the property is a function of the structural attributes (such as number of bathrooms, square footage of the property and so on), neighborhood attributes (such as school quality and local crime rate), and environmental attributes (such as distance to the shoreline and view of the resource). Spatial dependence can be incorporated into the model in one of two ways. The first method is to estimate a spatially lagged dependent variable, which assumes that the spatially weighted sum of the neighborhood property prices is an explanatory variable in the model. The second method is to estimate a spatial-error hedonic model, which assumes that spatial dependence arises due to omitted variables or measurement errors

\footnotetext{
${ }^{6}$ The authors thank the Pensacola Association of Realtors for allowing access to their property transactions database.
} 
that vary spatially. A robust Lagrange Multiplier (LM) test indicated that a spatially lagged model is appropriate. ${ }^{7}$ Our spatial-lag hedonic model takes the form $P_{i t}=\alpha+\beta_{i t} x_{i t}+\delta_{1} r 1_{i t}+\delta_{2} r 2_{i t}+\delta_{8} r 3_{i t}+\delta_{4} r 4_{i t}+\gamma v_{t i}+\lambda W P+\delta_{t}(1)$

where $P_{i t}$ is the sales price of the $i t h$ property at time $t, \boldsymbol{x}_{i t}$ is a vector of structural attributes and the sales date of property $i, r l_{i}$ through $r 4_{i}$ are row dummies where $r k_{i t}$ is equal to 1 if the property is located in Row $k$, and 0 otherwise, $v_{i t}$ is the viewshed of each property, $\varepsilon_{i}$ is a random error term. ${ }^{8}$ In the model, $\lambda$ is the spatial autoregressive parameter, while $\mathbf{W P}$ is the vector of spatially lagged dependent variables for the weights matrix, $\boldsymbol{W}$. The coefficients to be estimated are $\alpha, \beta, \delta, \gamma$, and $\lambda$.

In the hedonic framework, the partial derivative of Equation (1) with respect to each housing attribute variable yields the corresponding implicit price of the housing attribute. As the implicit values of locating a property in each row are given by the relevant row dummies in a log-linear specification and the implicit row prices vary with property values, the implicit value of locating a property in Row $k$ is<smiles>[13CH3][13CH3]</smiles>

where $\hat{F}_{i}$ is the fitted value for property $i$.

\section{Value Capture Tax}

We follow the framework set out by Parsons and Noailly (2004) to estimate the value capture tax for properties located in each housing row. The first step in measuring the tax

\footnotetext{
${ }^{7}$ Robust LM tests showed spatial-lag dependence $\left(\chi^{2}=12.995 ; p\right.$-value $\left.=0.000\right)$ but indicated no spatialerror dependence $\left(\chi^{2}=0.985 ; p\right.$-value $\left.=0.321\right)$.

${ }^{8}$ Block 5 is the omitted block in the model.
} 
is to calculate the proximity index for each row relative to Row 1 . For any Row $k$, the proximity index $\left(A_{k}\right)$ is the ratio of the proximity value in that row relative to the proximity value in Row 1 . So,

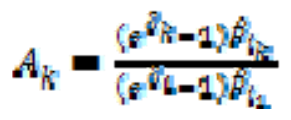

Following Parsons and Noailly (2004), we estimate $t_{t_{k}}$ by using the median fitted values for property prices in row $k$.

As the cost of nourishment projects and number of homes per row is known, a perhousehold baseline tax rate can be estimated using the following equation

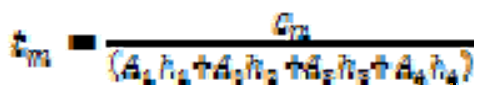

where $C_{m}$ is the cost of the nourishment project $m, t_{m}$ is the baseline household tax rate, and $h_{k}$ is the number of homes in Row $k$. Finally, the value capture tax is calculated using the proximity index shown in Equation (3). For Row $k$, the household value capture tax is $\tau_{i}=A_{k-1} t_{m}$

As the proximity index for homes located in Row 1 is equal to 1 , the per-household value capture tax for a home in Row $1\left(\tau_{1}\right)$ is the baseline tax rate. As the proximity index decreases for homes located farther from the shoreline, the per-household value capture taxes will decrease accordingly. This adheres to the benefit principle of the taxation system as homes located farther from the shoreline receive less benefits from nourishment projects, and so, their finance burden is reduced proportionately. 


\section{Results}

In estimation, we test both a spatial-lag (Model 1) and a log-linear hedonic model (Model 2) with $\log P$ as the dependent variable via maximum likelihood. ${ }^{9}$ The regression results are presented in Table 2. Comparing the models, the magnitudes and statistical significance of all parameters is largely unaltered; however, a likelihood ratio test signals that the spatial-lag model is preferred. ${ }^{10}$ In Model 1, the spatial autoregressive parameter, $\lambda$, is positive and significant, suggesting that spatial dependence in property prices exists. In Model 1, having controlled for spatial dependence, property prices increase with the number of bathrooms, the size of the garage, and the size of the home (although the magnitude of the coefficient on SQFT is small, which we believe is primarily due to the uniform nature of the beach properties). As expected, the price of the property is negatively correlated with age, as older homes sell for less, all else being equal. The quadratic specification on age captures the increasing marginal effects of age on a property's value. Finally, the year dummies illustrate the large run up in local property prices from 2004 onwards.

The key variables of interest are our measures of viewshed and beach access. The view coefficient is positive indicating that homeowners are willing to pay a premium for a view of the Gulf. Based on the sample average, the size of the VIEW coefficient suggests that a one-degree increase in a property's viewshed increases its value by $\$ 1,603$. This is larger than the findings of Bin et al. (2008), in which they find a median willingness to

\footnotetext{
${ }^{9}$ The spatial autocorrelation estimation was implemented within the GeoDa v.0.9.5-I (2005) environment. GeoDa is a geospatial analysis software package developed at Arizone State University for spatial process modeling. ${ }^{10} \chi^{2}=13.123 ; p$-value $=0.000$
} 
pay for an equal increase in viewshed of $\$ 995$ for properties along the North Carolina coastline. Results for proximity (Row1 through Row4) indicate that, as expected, there is an increase in value for properties located closer to the Gulf. Row1 represents a Gulf front property and Row 5 is the excluded Row. Results from the spatial-lag model specification indicate that a Gulf-front property is worth approximately $53 \%$ more than an equivalent home located in Row5. We also find that the proximity premium declines to $25 \%, 23 \%$, and $15 \%$ for properties located in Row 2, Row 3, and Row 4 respectively.

We use the proximity values from the spatial lag model to estimate the tax indices $\left(A_{K}\right)$ shown in Equation (3), using the median fitted values for property prices in each row (Table 3). Table 4 provides the actual number of properties located in each row along the renourished strip of the two-mile residential portion of the beach and the estimated value capture tax. Before discussing the estimated value capture taxes, some preliminary observations are required. First, we use an estimate of $\$ 15$ million, based on the cost of the previous two renourishment projects at the beach, as the project cost estimate, $C_{m}$. We pro-rate the cost based on the proportion of the project that nourishes the residential portion of the beach. ${ }^{11}$ Next, we assume that the residential portion of the renourishment project is paid for entirely through the taxation system. As suggested by Black et al. (1990), beach access fees can also form a part of the payment mechanism. However, in our analysis, as only the residential portion of the beach is considered, we feel that it's appropriate to ignore any beach access fees that could be charged for this section of the project. Finally, we impose the restriction that only homes in the first four rows

\footnotetext{
${ }^{11}$ The total length of the beach renourishment is 8.2 miles. The cost of nourishing the 2-mile residential strip is then estimated as $((2 / 8.2) * \$ 15$ million $)$.
} 
contribute toward the tax. This is supported by our proximity values, and results from other studies, that typically show that the implicit value of living close to the given resource diminishes quickly for homes behind the first row (Bensen et al. 1997; Major 2003; Parsons and Noailly 2004).

We estimate an annualized tax payment, assuming two different expected project life spans of 5 years and 10 years, to form what may be considered as lower and upper-bound estimates, as renourishment of the region's beaches typically takes place over this time period. We estimate an annual value capture tax payment for Gulf-front properties of $\$ 2,903$ for renourishment projects recurring every 10 years to $\$ 5,807$ for 5-year projects. ${ }^{12}$ As implied by the tax indices, the annual tax payments decrease as properties move inland, to between $\$ 1,385$ and $\$ 2,770$ (for 10 -year and 5-year projects respectively) for Row 2 properties, $\$ 1,270$ and $\$ 2,540$ for Row 3 properties, and $\$ 842$ and $\$ 1,684$ for Row 4 properties.

\section{Conclusion}

We estimate a spatial lag hedonic property price model to measure the proximity values of homes located on Pensacola Beach, FL. Based on the benefit principle, we propose a value capture tax imposed on local residents to finance the recurring costs of beach renourishment projects. As properties closer to the shoreline receive more of the erosion protection benefits of the renourishment projects, the value capture tax is designed to levy the financing burden in a manner that approximates the distribution of benefits. Using

\footnotetext{
${ }^{12}$ All figures are in dollars for the year of the project. For presentation purposes, annual payments are calculated on a linear basis as the tax per-household in Block $k$ divided by the assumed life of the project, thus ignoring potential compounding interest rate issues.
} 
lidar data on the topographic surface of the coastal area, we include a measure of viewshed from each property to account for the role of view on local property prices. We reason that the coefficients on row dummy variables represent the proximity value associated with a property located on each row. Model results indicate an annual tax payment of $\$ 2,903$ for Gulf-front properties, assuming a 10-year expected lifetime for each renourishment project. The tax payment then declines to $\$ 1,385$ for Row 2 properties, $\$ 1,270$ for Row 3 properties, and $\$ 842$ for Row 4 properties, again assuming a 10-year useful life of a project. While an annual payment for Gulf-front properties may seem high, it is important to note that the average property price for Gulf-front properties in our sample was approximately $\$ 1.2$ million. Further, the tax payment will vary based on the longevity of the renourishment project. For example, if a tropical storm or hurricane impacted the area, then further renourishment may be warranted, requiring an adjustment to the payment schedule. 


\section{References}

Anselin, L. 2002. Under the Hood: Issues in the Specification and Interpretation of Spatial Regression Models. Agricultural Economics 27:247-267.

Bensen, E.D., J.L. Hansen, A.L. Shwartz JR. and G.T. Smersh. 1997. The Influence of Canadian Investment on U.S. Residential Property Values. Journal of Real Estate Research 13(3): 231-249.

Bin, O., T.W. Crawford, J.B. Kruse, and C.E. Landry. 2008. Viewscapes and Flood hazard: Coastal Housing Market Response to Amenities and Risk. Land Economics 84(3): 434-448.

Black, D.E., L.P. Donnelley, and R.F. Settle. 1990. Equitable Arrangements for Financing Beach Nourishment Projects. Ocean and Shoreline Management 14: 191-214.

Bond, M.T., V.L. Seiler, and M.J. Seiler. 2002. Residential Real Estate Prices: A Room with a View Journal of Real Estate Research 23: 129-137.

Bourassa, S.C., M. Hoesli, and V.S. Peng. 2003. Do Housing Submarkets Really Matter. Journal of Housing Economics. 12: 12-28. 
Doss, C.R., and S.J. Taff. 1996. The Influence of Wetland Type and Wetland Proximity on Residential Property Values. Journal of Agricultural and Resource Economics 21: 120-129.

Florida Department of Environmental Protection (FDEP). 2008. "To develop and implement a long term regional proactive beach management program for the state of Florida." Available: http://www.dep.state.fl.us/beaches/programs/bcherosn.html.

Irwin, E.G., and N.E. Bockstael. 2002. Interacting Agents, Spatial Externalities and the Evolution of Residential Land Use Patterns. Journal of Economic Geography 2: 31-54.

Kim, C., T. Phipps, and L. Anselin. 2003. Measuring the Benefits of Air Quality Improvement: A Spatial Hedonic Approach. Journal of Environmental Economics and Management 45(1): 42-39.

Landry, C.E., A.G. Keeler, and W. Kriesel. 2003. An Economic Evaluation of Beach Erosion Management Alternatives. Marine Resource Economics 18:105-127.

Major, C. 2003. The Beach Study: An Empirical Analysis of the Distribution of Coastal Property Values. Working paper, Pennsylvania State University. Available: http://forms.gradsch.psu.edu/diversity/menair/2003/major.pdf 
Parsons, G.R., D.M. Massey, and T. Tomasi. 1999. Familiar and Favorite Sites in a Random Utility Model of Beach Recreation. Marine Resource Economics 14:299-315.

Parsons, G.R., and M. Powell. 2001. Measuring the Cost of Beach Retreat. Coastal Management 29: 91-103.

Parsons, G.R., and J. Noailly. 2004. A Value Capture Property Tax for Financing Beach Nourishment Projects: An Application to Delaware's Ocean Beaches. Ocean and Coastal Management 47: 49-61.

Paterson, R., and K. Boyle. 2002. Out of Sight, Out of Mind? Using GIS to Incorporate Visibility in Hedonic Property Value Models. Land Economics 78: 417-425.

Pilkey, Jr., O.H., and K.L. Dixon. 1996. The Corps and The Shore. Washinton D.C. Island Press.

Pompe, J.J., and J.R. Rinehart. 1995. Beach Quality and the Enhancement of Recreational Property Values. Journal of Leisure and Research 27(2): 143-154.

Pompe, J.J., and J.R. Rinehart. 1999. Establishing Fees for Beach Protection: Paying for a Public Good. Coastal Management 27: 57-67. 
Tse, R.Y.C. 2002. Estimating Neighborhood Effects in House Prices: Towards a New Hedonic Model Approach. Urban Studies 39: 1165-1180. 
Table 1 - Definitions and Summary Statistics for Variables for Pensacola Beach, FL

Properties $(n=101)$

\begin{tabular}{|c|c|c|c|}
\hline Variable & Definition & Mean & Std. Dev. \\
\hline Price & House sales price adjusted to 2007 dollars & $577,781.30$ & $426,971.30$ \\
\hline Bath & Number of bathrooms & 2.34 & 0.75 \\
\hline Sqft & Total structure square footage & $1,853.47$ & 640.01 \\
\hline Age & Age of house & 29.61 & 11.48 \\
\hline Garage & Size of garage (per car) & 1.12 & 1.13 \\
\hline Yr1998 & House sale in $1998(=1)$ & 0.02 & 0.14 \\
\hline Yr1999 & House sale in $1999(=1)$ & 0.06 & 0.24 \\
\hline Yr2000 & House sale in $2000(=1)$ & 0.13 & 0.34 \\
\hline Yr2001 & House sale in $2001(=1)$ & 0.08 & 0.27 \\
\hline Yr2002 & House sale in $2002(=1)$ & 0.19 & 0.39 \\
\hline Yr2003 & House sale in $2003(=1)$ & 0.08 & 0.27 \\
\hline Yr2004 & House sale in $2004(=1)$ & 0.19 & 0.37 \\
\hline Yr2005 & House sale in $2005(=1)$ & 0.09 & 0.29 \\
\hline Yr2006 & House sale in $2006(=1)$ & 0.08 & 0.27 \\
\hline Yr2007 & House sale in $2007(=1)$ & 0.12 & 0.33 \\
\hline Block 1 & House is located in Block $1(=1)$ & 0.16 & 0.37 \\
\hline Block 2 & House is located in Block $2(=1)$ & 0.10 & 0.30 \\
\hline Block 3 & House is located in Block $3(=1)$ & 0.28 & 0.45 \\
\hline Block 4 & House is located in Block $4(=1)$ & 0.31 & 0.46 \\
\hline Block 5 & House is located in Block $5(=1)$ & 0.16 & 0.37 \\
\hline View & Angular viewshed from property in degrees & 42.27 & 55.70 \\
\hline
\end{tabular}


Table 2 - Hedonic Property Price Model Results for Pensacola Beach, FL Properties

\begin{tabular}{lllllll}
\hline & \multicolumn{3}{c}{ Model 1-Spatial-lag } & \multicolumn{3}{c}{ Model 2-Log-linear } \\
Variable & Coefficient & Std. Error & $p$-Value & Coefficient & Std. Error & $p$-Value \\
\hline Constant & 11.656 & 0.329 & 0.000 & 12.255 & 0.344 & 0.000 \\
Bath & 0.124 & 0.054 & 0.055 & 0.131 & 0.064 & 0.064 \\
Sqft & 0.000 & 0.000 & 0.031 & 0.000 & 0.000 & 0.062 \\
Age & -0.023 & 0.012 & 0.061 & -0.028 & 0.014 & 0.052 \\
Age & 0.000 & 0.000 & 0.064 & 0.000 & 0.000 & 0.054 \\
Garage & 0.087 & 0.027 & 0.001 & 0.085 & 0.033 & 0.010 \\
Yr1999 & -0.064 & 0.210 & 0.759 & -0.046 & 0.250 & 0.853 \\
Yr2000 & -0.031 & 0.185 & 0.863 & -0.035 & 0.221 & 0.874 \\
Yr2001 & -0.023 & 0.196 & 0.906 & -0.024 & 0.234 & 0.334 \\
Yr2002 & 0.128 & 0.183 & 0.484 & 0.091 & 0.218 & 0.676 \\
Yr2003 & 0.237 & 0.196 & 0.226 & 0.227 & 0.233 & 0.334 \\
Yr2004 & 0.673 & 0.186 & 0.000 & 0.600 & 0.222 & 0.008 \\
Yr2005 & 0.545 & 0.201 & 0.007 & 0.536 & 0.240 & 0.028 \\
Yr2006 & 0.783 & 0.196 & 0.000 & 0.774 & 0.233 & 0.001 \\
Yr2007 & 0.361 & 0.191 & 0.059 & 0.346 & 0.228 & 0.133 \\
Block1 & 0.428 & 0.164 & 0.009 & 0.437 & 0.195 & 0.028 \\
Block2 & 0.227 & 0.078 & 0.004 & 0.215 & 0.093 & 0.023 \\
Block3 & 0.210 & 0.105 & 0.046 & 0.240 & 0.125 & 0.059 \\
Block4 & 0.144 & 0.075 & 0.054 & 0.139 & 0.089 & 0.122 \\
View & 0.003 & 0.001 & 0.007 & 0.003 & 0.001 & 0.044 \\
Lamda $(\lambda)$ & 0.040 & 0.011 & 0.000 & & & \\
Obs & 101 & & & 101 & & \\
\hline \hline
\end{tabular}


Table 3 - Tax Indices

\begin{tabular}{cc}
\hline \hline Index & Spatial-lag Model \\
\hline $\mathrm{A}_{1}$ & 1.00 \\
$\mathrm{~A}_{2}$ & 0.48 \\
$\mathrm{~A}_{3}$ & 0.44 \\
$\mathrm{~A}_{4}$ & 0.29 \\
\hline \hline
\end{tabular}

Table 4 - Value Capture Tax (Annual Payment)

\begin{tabular}{cccc}
\hline \hline Block & Property Count & Spatial-lag Model \\
& & 5 -year & 10 -year \\
\hline 1 (Gulf-front) & 58 & $\$ 5,806.8$ & $\$ 2,903.4$ \\
2 & 41 & $\$ 2,770.1$ & $\$ 1,385.0$ \\
3 & 69 & $\$ 2,540.2$ & $\$ 1,270.1$ \\
4 & 63 & $\$ 1,683.6$ & $\$ 841.8$ \\
\hline \hline
\end{tabular}

